\title{
ERRATUM
}

\section{Hypertonic saline in severe traumatic brain injury: a systematic review and meta-analysis of randomized controlled trials - ERRATUM}

Elyse Berger-Pelletier, Marcel Émond, François Lauzier, Jean-François Shields, and Alexis F. Turgeon

doi:10.1017/cem.2016.12

In the original publication of "Hypertonic saline in severe traumatic brain injury: a systematic review and meta-analysis of randomized controlled trials," Elyse Berger-Pelletier's name was misspelled. The original has since been corrected.

The CFEM editors and Cambridge regret this error.

\section{REFERENCE}

Berger-Pelletier E, Émond M, Lauzier F, Shields J-F, and Turgeon AF. Hypertonic saline in severe traumatic brain injury: a systematic review and meta-analysis of randomized controlled trials. CFEM 2016;18(2):112-20.

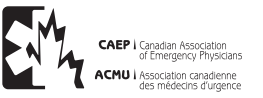

